\title{
Proposed Infrastructure Pricing Methodology for Mixed-Use Rail Networks
}

\author{
By: Francisco Calvo, Juan de Oña and Andrew Nash
}

This document is a post-print versión (ie final draft post-refereeing) of the following paper:

Francisco Calvo, Juan de Oña and Andrew Nash (2007) Proposed Infrastructure Pricing Methodology for Mixed-Use Rail Networks. Transportation Research Record: Journal of the Transportation Research Board, 1995, 9-16.

Direct access to the published version: http://dx.doi.org/10.3141/1995-02 


\title{
A PROPOSED INFRASTRUCTURE PRICING METHODOLOGY FOR MIXED-USE RAIL NETWORKS
}

Submitted in revised form: November 14, 2006

6.048 words +2 figures +1 table $=6.798$ words

Francisco Calvo ${ }^{1}$ (fjcalvo@ugr.es), Juan de Oña ${ }^{1}$ (jdona@ugr.es) and Andrew Nash ${ }^{2}$

(andy@andynash.com)

${ }^{1}$ Department of Civil Engineering, University of Granada, E.T.S. de Ingenieros de Caminos, Canales y Puertos, Avda. Severo Ochoa, s/n, 18071 - Granada, Spain.

Tel. +34 958 249452, Fax +34958 246138

${ }^{2}$ Institute for Transport Planning and Systems, ETH Zurich, Wolfgang-Pauli-Str. 15, 8093 - Zürich,

Switzerland

Tel. +41446336688

\begin{abstract}
A pricing methodology adapted to specific railroad infrastructures and the trains that use them is one way to ensure that railroad networks used by several different operators are used optimally. The diversity of railway networks (new lines and old lines) and services (long-distance and suburban passenger trains, freight trains, etc.) make it difficult to develop such a pricing methodology. This paper proposes a pricing methodology for a mixed use rail network designed to encourage efficient network use and thereby contribute to development of a sustainable transport system. The proposed methodology considers internal and external costs. It could be applied by different network operators (e.g. national rail networks) differently based on policy objectives. One feature of the pricing methodology is that it would partially subsidize a rail service's infrastructure charges based on the savings in external costs when a certain level of demand is met by railroad rather than road. The proposed methodology also considers the rail service operator's willingness to pay and public service issues. The paper describes how the proposed methodology would be applied for different train services. The conclusions show that under the proposed pricing methodology, charges would increase in the following order: suburban, regional passenger trains and freight trains (lowest) to high-speed trains (highest).
\end{abstract}




\section{A PROPOSED INFRASTRUCTURE PRICING METHODOLOGY FOR MIXED-USE RAIL NETWORKS}

\section{INTRODUCTION}

The opening of Europe's rail market has led to the introduction of several methods for pricing rail network access (a detailed analysis can be found in (1)). Despite the differences between these methods, they all follow one of two models: pricing according to the marginal social cost (MSC) or pricing according to full costs (FC). The main features of each model are:

- $\quad$ MSC - A marginal social cost pricing model recovers internal and external costs directly related to train operations. Since this method provides a direct connection between usage and costs, it is ideal for managing demand and helps to improve overall transport system efficiency. The main drawbacks are that it is difficult to estimate MC and it provides a low internal cost recovery (around 10 percent of the total infrastructure costs $(2,3)$ ). MSC is applied in Sweden, Switzerland and Denmark (1).

- FC - The objective of a full cost pricing model is total cost recovery. Therefore, charges are fixed above marginal costs (MC) either using Ramsey prices (RP) (increasing variable charges above MC for services that are less price-sensitive), or using a two-part tariff (comprising fixed and variable charges). It should be noted that FC methods do not actually pay the full infrastructure costs since these costs are so high that they would be impossible for operators to pay. In practice, up to 65 percent of the total cost (4) is recovered, while the rest is subsidized by the government. The main advantage of the FC pricing method is that cost recovery can be increased. Some of its main drawbacks are that charges are higher (which may affect demand); it is difficult to accurately estimate the actual cost of infrastructure investments; and levying fixed costs from infrastructure to operators is complicated, since they are less infrastructure-related. FC is applied in Germany, the United Kingdom, France, Italy and Spain (1).

At the domestic level, the decision as to which pricing system is applied has depended on several factors: the government budget allocated to the railroad, the degree of network congestion, and the importance of reducing transportation's external costs as a policy objective.

At the European level, the wide variety of different train types (freight, suburban and regional, long distance and high speed) using different infrastructures (conventional and high-speed lines) to provide different types of service makes it difficult to develop a uniform pricing system. Moreover, mixed traffic also raises capacity issues that must be included in the pricing system.

This research developed a flexible pricing methodology that can be adapted to each country's transportation policies and the diversity of railroad lines and rail transport services. The proposed methodology consists of a basic framework that can be easily adapted to the internal and external determining factors of any rail network, in such a way that it offers many possibilities for charging prices between MSC and FC. Several determining factors are taken into consideration to adapt the basic framework to specific cases: the rail service's sensitivity to charges for infrastructure use (RP), the rail service's contribution to transportation system sustainability, the rail service's social impact and specific features of the infrastructure.

The following section describes the proposed pricing methodology. The third section describes how the methodology would be applied for several examples. The final section presents conclusions.

\section{PROPOSED MIXED NETWORK PRICING METHODOLOGY}

The European rail system is extremely diverse. It is made up of national networks of rail lines of different qualities and is used for different kinds of service (passenger trains at different speeds and traveling distances, and freight trains). This diversity presents a huge variety of management and financing issues. Figure 1 illustrates the framework for the pricing methodology proposed in this 
research designed to address this diversity (it extends an earlier methodology proposed by the authors (1)). The proposed methodology consists of three sets of charges that capture both variable and fixed costs.

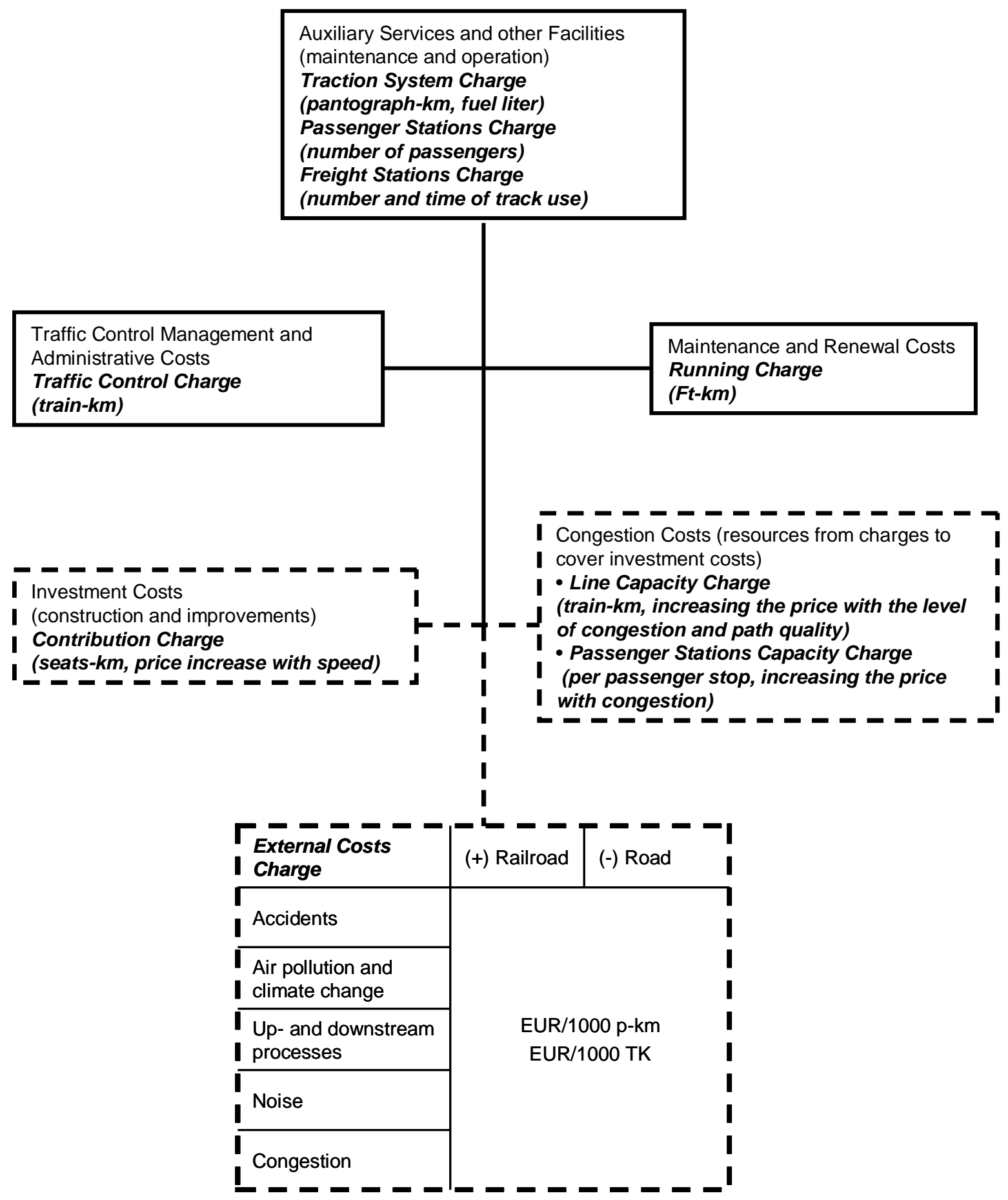

Ft-km: fictitious ton-km. p-km: passenger-km; TK: net ton-km

FIGURE 1 Schematic overview of the proposed mixed network pricing methodology.

The proposed methodology consists of three main parts: the first is designed to recover direct costs incurred by the infrastructure manager; the second is designed to increase cost recovery by applying charges to specific rail services related to their operators' willingness to pay and demand for 
infrastructure access; and the third is designed to consider external costs (i.e. include the benefits of shifting traffic to rail). Each part of the methodology is described below.

\section{Infrastructure Manager's Direct Costs}

The first three charges recover the infrastructure manager's direct costs for train traffic. They are:

\section{Auxiliary Services and Other Facilities Charges}

This includes charges related to the traction system (Traction System Charge) and use of stations (Passenger or Freight Stations Charge). These charges recover the maintenance and operating costs of these services and facilities. The parameters used to levy these charges are use-related: the Traction System Charge uses the pantograph-km for electric trains (related to the catenary wire wear and tear) and a volume of fuel consumed related charge for diesel trains (actual electricity and fuel consumed are paid separately); the number of passengers that board or alight trains is a direct measure of station usage, as well as the occupation of the tracks by freight trains (e.g. for shunting).

\section{Traffic Control Charge}

The Traffic Control Charge is designed to recover administration costs and railroad traffic management and control costs. Since these costs are generally the same for all trains, and therefore, except for special traffic, they are levied via the train-km parameter.

\section{Running Charge}

The Running Charge recovers the cost of track maintenance and renewal. It is levied through an adaptation of the Fictitious ton-km (Ft-km) parameter. Fictitious tons (a concept defined by UIC (5)) reflect track wear and tear due to train traffic better than other simpler parameters, such as the GTK (gross ton-km) or the train-km. In our proposed methodology the Ft-km method was modified to distinguish between conventional trains (locomotive+coaches or wagons) and self-propelled rail cars (distributed traction). It does this by taking into consideration axle load, composition, speed and weight of the trains according to formula (1):

$$
\mathrm{Ft}=\mathrm{S} *\left(\mathrm{Kp}, \mathrm{f}^{*} \mathrm{~T}+\mathrm{Kt} * \mathrm{Tt}\right)
$$

where:

$\mathrm{S}=$ coefficient that increases according to train speed (from $\mathrm{S}=1.00$ when $\mathrm{v} \leq 60 \mathrm{~km} / \mathrm{h}$ to 1.50 when $\mathrm{v}>250 \mathrm{~km} / \mathrm{h}$ )

$\mathrm{Kp}=$ coefficient allowing for the influence of passenger train axle-loads. It is equal to 1.00 for coaches, 1.20 for rail cars with $50 \%$ or more driving axles and 1.30 for rail cars with less than $33 \%$ driving axles

$\mathrm{Kf}=$ coefficient increasing from 1.15 to 1.45 based on the maximum axle-load of the hauled stock (freight)

$\mathrm{T}=$ gross tons hauled

$\mathrm{Kt}=$ coefficient that takes into account the usually high axle-load of the locomotive, and is equal to 1.40

$\mathrm{Tt}=$ weight of the locomotive, in tons.

\section{Additional Fees to Increase Cost Recovery}

The second set of charges is designed to provide revenues to partially offset the cost of infrastructure investments. The charges are related to rail operators' willingness to pay and their demand for infrastructure access. They are: 


\section{Contribution Charge}

The Contribution Charge recovers investment costs (construction of new lines, stations, electrification, installation of a new traffic control systems, etc.) by levying a percentage of the annual amortization cost to operators based on the seats-km parameter and by incrementing the charge based on speed-of-service. The Contribution Charge is based on the RP since it increases the pricing level above MC for services that can afford to pay it, specifically long distance and high-speed trains. Since these trains have higher capacity and speed, and are free of public service constraints they can be operated profitably and a share of their profits can be used to help defray infrastructure investment costs.

\section{Capacity Charge}

The Capacity Charge is designed to recover congestion costs, which are related to the opportunity cost of allocating a path to a specific operator and the increased risk of delays due to additional traffic. The capacity charge is divided into two parts: the line capacity charge and a station capacity charge (since station stops consume a significant amount of rail segment capacity). In levying the Line Capacity Charge, the train-km parameter was chosen to avoid penalizing slower suburban and freight train traffic; the price of this charge increases with the level of congestion (off-peak, intermediate and peak periods) and priority in path allocation. The station capacity charge is levied per passenger stop and also increases with the level of congestion since station stops occupy a platform track for a certain amount of time, which means it cannot be used for other services. The fees obtained from Capacity Charges should be reinvested in railroad infrastructure.

\section{Fees Related to External Costs}

The third type of charge is designed to take into account the externality benefits of shifting traffic to rail from other less sustainable modes of transportation. The pricing methodology does this by balancing the externalities between different modes of transport.

\section{External Cost Charge}

The purpose of the External Cost Charge is to account for the reduction in external costs brought about by shifting traffic (freight and passenger) from modes that have higher external costs (e.g. roads) to rail. The External Cost Charge includes the most important transport sector external costs: accidents, pollution, climate change, up- and downstream processes, noise, and congestion.

The External Cost Charge is calculated by subtracting the external costs generated by the alternative mode of transport (generally roads) from the external costs generated by the rail transport. In cases where the alternative form of transport generates higher external costs than rail (and where it does not pay for the external costs it generates) the result will be a negative number (e.g. roadway transport external costs will be higher than railway external costs) resulting in a reduction in the railway access charge levied on the operator. Thus, the reduction in external costs obtained by switching transport to the rail mode is included in the charging methodology. Passenger-km and net ton-km are used as levying parameters because they enable easy comparison of the external costs for different means of transportation. In the event that an alternative means of transportation pays its external costs, only the external costs of railroads would be considered.

\section{APPLYING THE PRICING METHODOLOGY TO A SHARED RAIL NETWORK}

This section describes how the proposed pricing methodology would be applied to various types of rail services operated in a diversified network. Adjustment of the model to each specific case is based on selecting the costs to be levied, taking into consideration a series of constraints inherent to rail systems and factors based on economic and social policies. The section begins with a discussion of several factors that influence application of the pricing methodology. 


\section{Pricing Methodology Influence Factors}

\section{Railroad Network}

The main railroad network features that must be considered when applying the proposed charging methodology are:

- $\quad$ Rail Line Type - specifically whether the lines are new high speed lines or conventional lines. The quality of new lines is generally much higher than conventional lines. Furthermore, the cost of new lines is known and has not yet been amortized, while the present value of older lines (that includes construction and renewals) is generally unknown or may be considered as at least partially amortized.

- Rail Line Congestion - congestion can occur in the lines around major cities and other line sections, such as border crossings and mountain passes.

\section{Transportation Services}

Transportation services addresses the shared use of railroad infrastructure. The proposed methodology considers short, intermediate and long-distance passenger transportation services (for long-distance a distinction is made between conventional and high-speed services) and freight services.

\section{Transportation System Sustainability}

The transportation system sustainability addresses external costs of transport. According to a study (6) carried out on EU-17 (Germany, Austria, Belgium, Denmark, Spain, Finland, Greece, Ireland, Italy, Luxembourg, Netherlands, Portugal, United Kingdom, Sweden, Switzerland and Norway), the external costs of transportation (not including congestion) came to 650,275 million Euros in the year 2000 . About $85.6 \%$ of that amount was generated by road and rail transport (83.7\% for roads and $1.9 \%$ for railroads). The highest external costs are generated by accidents, air pollution, climate change, up- and downstream processes and noise. Table 1 summarizes the road and rail external costs for passenger and freight transport in Europe.

Total road congestion-related costs were estimated at 63,000 million Euros. Railroad congestion costs are not considered external since the infrastructure manager must assign a path to an operator before the service can use the infrastructure (and therefore, infrastructure usage is not an operator's unilateral decision). Moreover, operators must pay for the capacity they consume.

\begin{tabular}{|l|c|c|c|c|}
\hline \multirow{2}{*}{ MAIN EXTERNAL COSTS } & \multicolumn{2}{|c|}{ Passengers (Euros/1000 p-km) } & \multicolumn{2}{|c|}{ Freight (Euros/1000 TK) } \\
\cline { 2 - 5 } & Road & Railroad & Road & Railroad \\
\hline Accidents & 32,4 & 0,8 & 7,6 & 0,0 \\
\hline Air pollution and climate change & 29,7 & 13,1 & 59,7 & 11,5 \\
\hline Up- and downstream processes & 5,0 & 3,4 & 8,8 & 2,4 \\
\hline Noise & 5,1 & 3,9 & 7,4 & 3,2 \\
\hline Congestion & 8,8 & 0,0 & 10,2 & 0,0 \\
\hline Total & $\mathbf{8 1 , 0}$ & $\mathbf{2 1 , 2}$ & $\mathbf{9 3 , 7}$ & $\mathbf{1 7 , 1}$ \\
\hline
\end{tabular}

TABLE 1 Average external costs of road and rail transportation in the EU-17 (6)

Table 1 shows that external costs generated by road transport are between four times (passengers) and almost six times (freight) higher than for rail transport. Given the difference in external costs, overall transport system sustainability would improve more by shifting freight from road to rail haulage than by shifting passenger traffic.

Since one of the proposed pricing methodology's key aims is to increase the efficiency and sustainability of the transportation system as a whole, this difference in costs is considered when applying the pricing methodology. Specifically, the methodology subsidizes services for their cost of railroad infrastructure use based on their reduction in external costs over alternatives. 


\section{Public Service}

Public service takes into account the fact that many railroads must guarantee a specified level of access to certain geographic areas (i.e. service is operated as a public service rather than as a profit making enterprise). The most obvious cases are large urban conglomerations where public transport is needed to provide high capacity access, and, at the other extreme, lightly populated and/or isolated areas that need transport service but do not have the demand to justify the maintenance and renewal of rail service.

\section{European Union Transportation Policies}

Directive 2001/14/EC (7) defines the basic criteria for levying charges for the use of railroad infrastructure. It allows charging systems to consider charging for the external costs generated by roads and railroads to improve the efficiency of the transportation system as a whole. Therefore, it allows a railroad infrastructure's charging system to consider the external costs that other modes of transportation do not pay in setting charges, when these costs exceed the equivalent external costs of rail. Thus this directive validates the approach proposed in this methodology (External Cost Charges) of reducing railroad charges to account for the difference in external costs between railroads and roads.

The directive also allows infrastructure charges to vary depending on the type of rail service. This flexibility is based on the RP and its aim is to increase infrastructure cost recovery. Thus, the directive allows pricing to be higher than MC, in cases when the market can take it (high-speed and long distance services), and minimal pricing (costs directly related to running the train) for services that are more sensitive to costs and that are of higher public interest (freight and suburban and regional passenger services). The directive also allows infrastructure charges to be waived for services provided through contracts with public authorities because they are of public interest.

The EU's 2001 White Paper on Transport (8) recommends revitalizing railroads as a key tool for building a sustainable transportation system, particularly with respect to freight transport. To help balance transportation modes, the white paper promotes financial support for the development and improvement of railroad infrastructure using EU funding, domestic budgets and private investors. Another measure recommended in the white paper to improve freight transportation quality is allowing freight operators to access slots in intermediate periods (not just off-peak). Without some priority in path allocation, freight operators will be unable to offer journey times competitive with road times, since otherwise freight trains must stop during peak periods increasing their travel time.

Concerning FC levying, the European Commission (9) acknowledges that it does not seem feasible to levy FC for infrastructure charges given the huge magnitude of railroad infrastructure investment and the lack of detailed financial records Finally, the huge difference in investment cost and amortization rates between new lines and conventional lines means that levying FC costs on conventional lines should be restricted.

Finally, due to the huge cost of railroad infrastructure, an infrastructure manager's annual profit and loss accounts might compromise government accounting if the deficits were simply transferred to the government. To prevent this type of deficit transference, and pursuant to EU regulation ESA 95 (10), infrastructure managers must show a commercial income that is higher than 50 percent of production costs (not including financing costs). This economic constraint forces infrastructure managers to maximize revenue. This means that if a transport service is subsidized by the government, the public administration must transfer the subsidy directly to the railroad operator and the operator must use these funds to pay the infrastructure manager.

\section{Adjusting the Pricing Model to Rail Services}

The basic charges included in the proposed pricing model (Running Charge, Traffic Control Charge and Charge for using Auxiliary Services and other Facilities) are always collected from train operators according to Directive 2001/14/EC (7). Adjusting the proposed pricing methodology to a specific case consists of compensating the Contribution Charge and, sometimes, the Running and Capacity Charges with the External Cost Charge and public funding. This section outlines how the proposed pricing 
methodology would work for several general train types. (Note that these descriptions represent common examples but there is a significant amount of variety throughout Europe.)

\section{Suburban Trains}

The top speed of suburban trains is usually under $100 \mathrm{~km}$ per hour and their maximum frequency is during peak hours. Service is generally provided with electric train units.

Suburban trains use conventional rail lines near large cities and stop frequently. Often the lines they use are congested due to the diversity of traffic their concentration during peak hours. Therefore the Capacity Charge for suburban train services is very important.

Suburban train service is generally expensive to operate because it must meet a very concentrated demand in a short time period, and therefore requires a huge supply of personnel, rolling stock and auxiliary facilities which are underused for long periods each day. As if this were not enough, methods for improving financial performance are often very limited; ticket prices could be increased, but "social prices" are set to guarantee mobility to the entire population. Given these conditions, it is clear that suburban train service cannot afford to pay infrastructure charges above MC.

The most salient feature of suburban trains is that they are operated as a public service. Due to their enormous transportation capacity, they are essential for providing mobility in large cities and they contribute significantly to improving metropolitan area quality of life by reducing congestion, accidents, air pollution and noise pollution. Given these major social advantages, the compensating effect of External Costs Charge will be important.

In summary, suburban rail service operators should pay the Running Charge at the MC level; the public transport system authorities should provide funding to pay the costs not covered by the External Costs compensation and/or to partially subsidize operators for some of the charges levied on suburban rail services.

\section{Regional Trains}

The top speed of regional trains is usually around $120 \mathrm{~km}$ per hour. They make few stops, so they offer a higher commercial speed than suburban trains. These are intermediate distance services of 50$250 \mathrm{~km}$. The rolling stock used is often self-propelled rail cars, although sometimes conventional trains are also used.

Regional trains usually link large cities and towns to less populated areas, traveling along shared conventional lines. Congestion issues appear in the line sections close to large cities. Regional services often are scheduled during peak hours providing access to employment, shopping and leisure activities in cities.

Regional trains face strong competition from private automobiles. Since regional rail services often have limited frequency, use older rail lines and old rolling stock they are less convenient and comfortable than the automobile. In addition to these drawbacks, they are often less patronized because they serve less densely populated areas. Since they are a public service, it is hard to increase revenues by raising ticket prices. All of these factors mean that regional train services generally operate at a deficit and therefore are sensitive to levying charges above MC.

The public service nature of regional trains is based on the fact that they ensure accessibility to geographic areas which, due to a lower demographic and economic development, lack transportation infrastructures and services. Sometimes such transportation services are maintained as an alternative to private vehicles, in order to reduce accidents, pollution and congestion in the access to cities. These circumstances are taken into consideration by public authorities, which frequently subsidize regional train service.

In summary, the factors outlined above (travel along un-modernized lines that are congested in access to big cities, inability to support charges above MC, public service and transportation system sustainability) justify subsidizing regional rail services to cover part of the Running (fixed at MC), Contribution and Capacity Charges that are not compensated by the External Costs Charge in the proposed pricing methodology. 


\section{Conventional Long-Distance Passenger Trains}

Conventional long distance passenger trains generally reach top speeds of around $140 \mathrm{~km}$ per hour and make fewer stops than regional trains. They serve trunk lines at distances of more than $250 \mathrm{~km}$.

Long-distance rail services usually link important cities. They travel along corridors with high demand, so normally they offer high capacity. Generally, high performance trains are used for these services (both conventional trains and in electric train units). They travel on modernized lines that allow them to reach high speeds and offer quality service. The higher quality and more commercial pitch of these services (as opposed to the public service nature of suburban and regional trains) increases demand and allows them to charge higher ticket prices and make a profit. As a result, these trains can support paying charges higher than MC.

In order to attain high speeds, long-distance passenger trains make few stops (only at important stations). They take advantage of their priority over other traffic, so they impact the schedules of other trains regarding path availability and the risk of delays (traveling longer distances increases the risk of incidents). The fact that they depart from or arrive at important stations (often during peak hours) also implies a high consumption of station capacity. This means that Capacity Charges are a relatively important component of total charges.

Given the factors outlined above (profitability and the willingness to pay for priority in slot assignment) long distance trains can pay for the entire Running Charge and for the Capacity Charges.

Finally, these trains also contribute to a reduction in external costs since they reduce accidents, pollution and congestion by capturing a certain amount of the demand for roads, the transportation mode they compete with most directly.

\section{High-Speed Trains}

High-speed trains attain top speeds of more than $200 \mathrm{~km}$ per hour. Trains that are designed specifically for this service are used. Generally, they are electric train units.

High-speed trains share many features with conventional long-distance trains: they serve long distance trunk lines with a high transportation demand, offer a great many seats and make few stops.

The main difference between conventional long-distance services and those of high-speed trains is that high-speed trains generally use new lines and modern rolling stock designed specifically for high-speed traffic. This allows them to offer journey times that can compete with roads and airplanes, quality service on board, and more reliability and safety.

High-speed rail services have inherent features (operation in high-demand corridors with high-quality service) that make them more profitable than other rail services. Therefore, high speed train service is less sensitive to paying charges above MC. This, added to the fact that they use newlybuilt lines, justifies levying charges high enough to partly finance infrastructure construction and improvements. Based on these considerations, the cost recovery level of the Contribution Charge should vary according to RP; $25 \%$ can be taken as a maximum value, following the studies of the Spanish Ministry of Development (11).

In many cases, high-speed trains also use conventional lines to access big cities or simply because exclusive high-speed routes have not been finished. In such cases, high-speed trains consume as much capacity as conventional long-distance trains (due to priority over other traffic) and at stations. This should be reflected in the Capacity Charge.

The contribution of high speed train travel to transport system sustainability is similar to that of conventional long-distance trains, with the slight difference that high-speed trains also competes with air travel (which generates lower external costs cost due to accidents, noise and air pollution than roads, but higher external costs for climate change). (6)

In summary, high-speed rail service operators should pay all charges at the FC level, except for the Contribution Charge. 


\section{Freight Trains}

Freight trains normally link major production centers to each other and consumer centers. They travel at top speeds of around $100 \mathrm{~km}$ per hour. They offer a good alternative to road haulage (and, occasionally, to waterborne transport) over longer distances (more than 300-400 km).

In Europe, rail haulage faces strong competition from road haulage. Some of its drawbacks are: strong price competition, the difficulty in offering competitive journey times due to the lack of priority over passenger traffic; the lack of interoperability between networks; the difficulty of offering door-to-door service and the lack of rail access to certain production and attraction centers (such as industrial parks, freight transportation centers and central markets).

On the other hand, external costs due to road haulage are nearly six times higher than for rail haulage, so transferring freight demand to railroads can make a huge contribution to improving transport system sustainability. From the pricing perspective, over-charging for rail freight services could have the opposite effect: reducing railroad market share and increasing total external costs.

Furthermore, charging freight services for investment costs can not be justified since freight trains travel almost exclusively along conventional lines that have already been paid for or are close to being fully repaid. Further, high charges are not recommended for international routes, since they would led to unsustainable over-charging (4), especially in the case of freight traffic.

In summary, financial support will be needed to encourage shifting freight from roadway to rail. This support is needed for new and improved infrastructure (congested sections, inter-modality and access to markets), to ensure interoperability between national networks, to finance investment and fixed maintenance and renewal costs and to facilitate the use of off-peak slots by subsidizing their price. The proposed pricing methodology can be used to help reduce infrastructure charges based on the reduction in external costs.

\section{CONCLUSIONS}

The proposed infrastructure pricing methodology for a mixed-use rail network (summarized in Figure 1) can be adapted to all rail transport services and networks. At the same time, it complies with the EU's transportation and economic policy guidelines.

The proposed methodology is based on the implementation of six different charges from three charge categories summarized in Figure 2. The first charging category, infrastructure manager direct costs, includes: Running Charges, Traffic Control Charges and Auxiliary Services and other Facilities Charges. These represent the minimum level of pricing (costs directly related with train traffic) and they would be applied to all traffic.

The second charging category, infrastructure cost recovery, includes: Contribution Charges and Capacity Charges. These charges would be set based on the specific type of rail service operated. Prices would depend on factors, including transport system sustainability, public service and whether the service can afford to pay costs above MC. These charges are based on infrastructure (whether the service is using a new or old line) and the line's level of congestion.

The third charging category includes only one type of charge, the External Costs Charge. This charge captures the reduction in external costs obtained by meeting transport demand by rail rather than roads. Since studies have shown that rail transport has significantly lower external costs than road transport, this charge would actually represent a subsidy to rail operators which would be used to help pay for infrastructure investment and, in some cases, maintenance and renewal costs.

It should be noted that the magnitude of the External Costs Charge compared to the investment in rail network (which it is intended to help pay for), can be very significant, thereby justifying public subsidy of the railroad network. In Spain, for instance, according to INFRAS/IWW (6) and RENFE (12) data, railroads saved 1,493 million Euros in external costs in comparison to roads in 2004. On the other hand, investment in railroad infrastructure (construction, improvements, maintenance and renewals) came to 3,552 million Euros (13), which means that the savings in external costs compensates around 42 percent of the investment in railroad infrastructure. The importance of this last figure justifies the viability of the proposed method; moreover, the saving in 
external costs is even a little higher than the investment in maintenance and renewals and thus, the External Costs Charge is expected to be significantly greater than any capacity surcharge.

\begin{tabular}{|c|c|c|c|c|c|}
\hline CHARGE & Suburban & Regional & $\begin{array}{l}\text { Long } \\
\text { distance }\end{array}$ & $\begin{array}{l}\text { High } \\
\text { speed }\end{array}$ & Freight \\
\hline Contribution & 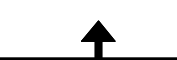 & 4 & 4 & $25 \%$ & 4 \\
\hline Capacity & & & & & 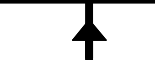 \\
\hline Running & $10 \%$ & $10 \%$ & & & $10 \% \uparrow$ \\
\hline Traffic control & & & & & \\
\hline $\begin{array}{l}\text { Auxiliary Services } \\
\text { and other Facilities }\end{array}$ & & & & & \\
\hline External costs & & & & & \\
\hline
\end{tabular}

Black boxes: Charge fully paid by operators; Gray boxes: Charge partially compensated by the External Costs Charge (\%: maximum percentage of the cost to be paid by operators); Orange boxes: saving in external costs; White boxes: Charge financed by the External Costs Charge and government subsidy if necessary; Arrows: transfer of monetary resources.

\section{FIGURE 2 Cost allocation and funding of the proposed pricing system.}

The External Costs Charge's compensating effect would be implemented as follows: the public transport administrations would pay to some operators the Capacity Charges and most of the Running Charge (on account of the External Costs Charge). Operators would then transfer these funds to the infrastructure manager (see Figure 2). This way, the infrastructure manager would obtain revenue for operating their productive resources, which would help them meet their revenue target of over $50 \%$ of production expenses. This would prevent them from transferring their deficit to the government accounting (as dictated by the EU's ESA 95 regulations (10)). Revenue obtained via the Capacity Charge should cover investment costs. After paying for the Capacity and Running Charges, the remaining funds derived from the External Costs Charge should be reinvested in railroad infrastructure.

Long-distance passenger and high-speed trains would pay a direct Capacity Charge. The funds obtained from the Charges for External Costs and Capacity for these rail services should also be used to finance the railroad network. The proposed pricing methodology would also recover investment costs via the Contribution Charge, which would levy a portion of investment costs (25 percent of the annual amortization cost) to the transportation services that could afford to pay prices over MC and that use new lines (high-speed trains). This charge would not be levied on services that are sensitive to high charges and that use conventional rail lines (suburban and regional trains, and freight trains). However, the latter would contribute towards financing the railroad network via the external costs charges compensation mechanism.

Investment costs not covered by the proposed funding methodology should be financed by the government authorities in charge of transportation infrastructure. Railroad system public funding is justified because in some cases it is a public service, and because the magnitude of railroad infrastructure investment costs is such that it is unadvisable to allocate it entirely to railroad operators $(7,9)$.

To summarize, adaptation of the proposed methodology for pricing of railroad infrastructure depending on the type of rail service would be as follows:

- Suburban and regional passenger trains: minimum pricing level. Compensation of Running (partially), Capacity and Contribution Charges, due to their large contribution towards transportation system sustainability (a very favorable external costs balance as compared to roads) and because they are a public service. 
- Freight trains: minimum level of pricing. Compensation of the Running Charge (fixed costs), Capacity Charge and Contribution Charge due to their large contribution towards an efficient and sustainable transportation system.

- Conventional long-distance passenger trains: intermediate level of pricing. They are levied, besides the Traffic Control and Auxiliary Services and other Facilities Charges, the entire Running Charge and the Capacity Charge. This last charge, together with the external cost balance, compensates the investment costs that are not levied.

- High-speed trains: maximum level of pricing. In addition to the payments levied to conventional long-distance passenger trains, they pay the Contribution Charge, thus partially financing investment costs. The Capacity and External Costs Charges help to compensate for the infrastructure investment costs that are not levied.

\section{REFERENCES}

1. Calvo, F. and de Oña, J. Opening of the European Railroad Network: a Lost Opportunity for European Unification. In Transportation Research Record: Journal of the Transportation Research Board, No. 1916, TRB, National Research Council, Washington, D.C., 2005, pp. 8-19.

2. Pittman, R. A Note on Non-Discriminatory Access to Railroad Infrastructure. US Department of Justice Antitrust Division. Economic Analysis Group (2003) Working Paper No. EAG03-5. Available at SSRN: http://ssrn.com/abstract=388382. Accessed March 27, 2004.

3. European Commission (1999). Calculating Transport Infrastructure Costs. Final Report of the Expert Advisors to the High Level Group on Infrastructure Charging (Working Group 1). ec.europa.eu/transport/infrastructure/doc/hlg-4-99-rep-en.pdf. Accessed March, 2003.

4. ECMT (European Conference of Ministers of Transport). Charges for the use of infrastructure in ECMT railways (Draft final report). ECMT/CS/CF(2005)1/REV1.

5. UIC (International Union of Railways) (1989). Classification of lines for the purpose of track maintenance and renewal. Leaflet $714 \mathrm{R}$.

6. INFRAS/IWW (2004). External Costs of Transport - Update Study. Final Report. INFRAS Zurich /IWW - Karlsruhe, October 2004.

7. European Commission. Directive 2001/14/EC of the European Parliament and of the Council of 26 February 2001 on the allocation of railway infrastructure capacity and the levying of charges for the use of railway infrastructure and safety certification. http://ec.europa.eu/transport/rail/legislation/infrastructure_en.htm. Accessed Jan. 17, 2003.

8. Commission of the European Communities. White Paper: European transport policy for 2010: time to decide $\operatorname{COM}(2001)$ 370, September 2001. http://europa.eu/eurlex/en/com/wpr/2001/act370en01/com2001 0370en01-01.pdf. Accessed Feb. 11, 2002.

9. Commission of the European Communities. White Paper: Fair Payment for Infrastructure Use: A Phased Approach to a Common Transport Infrastructure Charging Framework in the EU. White Paper. COM (98) 466 final, 22 July 1998. http://aei.pitt.edu/1136/. Accessed May 9, 2006.

10. European Commission. European system of accounts, ESA 95. June, 1996. http://forum.europa.eu.int/irc/dsis/nfaccount/info/data/esa95/en/titelen.htm. Accessed March 10, 2006.

11. Spanish Ministry of Development. Economic Memory of the Railway Law 39/2003. Madrid, 2003. (paper)

12. RENFE (National Spanish Railways). 2004 Annual Report. http://www.renfe.es/empresa/. Accessed Dec. 5, 2005.

13. Spanish Ministry for Development. El transporte y los servicios postales en España en cifras. Extracto del informe anual 2004. Centro de Publicaciones de la Secretaría General Técnica del Ministerio de Fomento. Madrid, 2005. Available at: https://www.fomento.es/cpmf/productdetails.aspx?productid=BT0021. 